\title{
EXHAUST GASES ENERGY USE IN THE COURSE OF GAS EXCHANGE IN DIESEL-FUELED VEHICLES
}

\author{
EVGENIY LAZAREV, VLADISLAV LAZAREV, ANDREY POMAZ \& ANDREY SALOV \\ The Department of Internal Combustion Engines and Electronic Automobile Systems, \\ South Ural State University, Russia
}

\begin{abstract}
Modern diesel building is developing in the direction of emissions with exhaust gases reduction and improvement of unit power, fuel efficiency, and engine lifetime. The achievement of high ecological, technical and economic indexes in diesel-fueled vehicles demands power efficient control and improvement of devices, which realized gas exchange processes. Exhaust gases energy is used in the gas exchange system of diesel-fueled vehicles. It is necessary for the improvement of diesel-fueled vehicles gas exchange efficiency to combine in one device the control of all of the following procedures: exhaust gases recirculation into the cylinder under small and no-load conditions for nitrogen oxide emission reduction; exhaust gases bypassing under turbocharger control on variable load operation for carbonic oxide, soot, and particulate matter emission reduction; exhaust gases use for air ejection in the process of circulation through charge air cooler under cooling conditions before air injection into the cylinder.
\end{abstract}

Keywords: diesel, gas exchange processes, exhaust gases energy, recirculation, turbocharger control, bypassing, ejection charge air cooling.

\section{INTRODUCTION}

Exhaust gases energy in the gas exchange system of power efficient compound engines (turbocharged diesels) can and should be used effectively. For its effective use, one device should control the following procedures:

1. Exhaust gases recirculation into the cylinder under normal, small, and no-load conditions for reduction of nitrogen oxide emission with exhaust gases.

2. Exhaust gases bypassing under turbocharger control on variable load operation for preventing of engine running on rich mixtures and reduction of carbonic oxide, soot, and particulate matter emission with exhaust gases.

3. Air circulation through charge air cooler (CAC) by ejection with the help of exhaust gases.

\section{EXHAUST GASES RECIRCULATION AND BYPASSING AS ELEMENTS OF GAS EXCHANGE IN TURBO DIESELS}

Exhaust gases recirculation presupposes heat recovery by their part delivery into the cylinder for repeated use as working medium during starting up. It is an effective means of starting up improvement, heating period acceleration, parts resin formation reduction under negative temperatures, reduction of nitrogen oxide, and increasing of fuel combustion process control under small and no-load conditions. However, under turbo charging conditions exhaust gases recirculation demands solution of several issues concerning choice of their selection and delivery places, criteria determination of bypassing gases condition and amount, and design of devices, that realize and regulate bypass. These problems worsen, when one or another way of turbocharger control is used for spin moment improvement, as the use of additional recirculation device complicates the control system. 
Turbocharger control is done in the most effective way by using of exhaust gases bypass during going out of the cylinder passing the turbine over at particular load with a help of automatically controlled bypassing device. This device as an element, that regulates the bypass channel area of passage, has valve, slide or valve-type shutter. Devices with valves or valve-type shutters are the most popular. Bypass control device at engine shaft rotation frequency, which corresponds with maximum output, passes a part of gas flow omitting turbine and automatically controls bypass intensity due to frequency reduction towards the mode of maximum spin moment. In some cases, the bypass control device is used as the shifting turbine device from impulse mode into constant gas pressure mode.

Under conditions of bypass control, the bypassed part of gas flow passes over the turbine and goes to the exhaust manifold pipe and then to the atmosphere. Exhaust gases bypass process is accomplished along whole control system of full-load curve of transport and traction vehicles, including maximum engine shaft rotation frequency at no-load condition. Taking into consideration this fact, we can conclude that it is necessary to use bypassed part of exhaust gases for recirculation, directing it to the cylinder on needed modes of engine.

Well-known freestanding units solve one of the following problems: exhaust gases recirculation or bypass control of the turbine. The main drawback of two freestanding units use is that it makes their drive system much more complicated. In addition, every unit needs a separate drive like Isenburg et al. [1].

The drive system can be simplified by using of the integrated element, which is controlled by the specified program and performing exhaust gases recirculation and bypass turbine control in particular order [2]. Valve and valve-type shutter devices or head pilot valve assemblies can be used as the element in such units. Head pilot valve assemblies are least studied devices of this type. In comparison with other types, they have several advantages, including compactness and ease of control.

Air ejection with the help of exhaust gases energy can be used for its circulation through the charge air cooler (CAC) and its cooling after turbocharger and before its delivery to the cylinder.

The next step in exhaust gases use in gas exchange system and devices, that regulate them, is gradual combining of exhaust gases recirculation to the cylinder function with the function of bypass turbocharger turbine control, and ejection charge air cooling in one device.

\section{POSSIBLE WAYS OF EXHAUST GASES ENERGY USE IN GAS EXCHANGE PROCESS}

Separate ways of diesel work control with the use of bypass turbocharger turbine control, recirculation of exhaust gases flow part to the cylinder and exhaust gases ejection for air circulation are well known. In such a case, freestanding units are used, and each of them solves only one of the problems: exhaust gases recirculation, bypass turbine control or exhaust gases ejection for air circulation through the engine coolant radiator. The use of the three freestanding units makes their drive system much more complicated. In this case, separate drive for every unit is needed, as well as, the full flow of exhaust gases for ejection, including normal, small and no-load conditions. This fact complicates the maintenance of heat exchange and diesel parts heat condition in particular working modes.

The way of diesel working control, intending device working control in a combination with a bypass turbine control and exhaust gases recirculation function, is realized by using of the integrated element, which is controlled by the specified program and performing exhaust gases recirculation and bypass turbine control in particular order. In this case, the part of exhaust gases, which is passing over the turbine in the process of bypass control, under small and no-load conditions recirculates to the cylinder. Due to increase in load, when 
recirculation of exhaust gases becomes economically impractical, this part of exhaust gases flow is emitted to the atmosphere. This fact is a main drawback of this way of control and device of its maintenance. Exhaust gases flow part energy is still quite high, but in this case, it is not used for diesel working under normal and small load conditions.

\section{THE WAY OF GAS EXCHANGE CONTROL IN DIESEL WITH TURBO CHARGING}

For gas exchange system with the use of exhaust gases energy improvement, it is necessary to achieve automatically controlled combination of exhaust gases recirculation into the diesel cylinder under normal, small and no-load conditions, with turbocharger turbine control at variable load operation, and air ejection for its circulation through charge air cooler and its cooling before delivery to the cylinder. Such way helps to use a part of exhaust gases for air circulation through intermediate charge air cooler with combination of functions of ejection cooling and bypass turbocharger turbine control due to the stop of the exhaust gases recirculation into the cylinder [3].

In a case of bypass turbocharger turbine control stop, the device allows to use exhaust gases full flow energy after the turbine for air circulation through intermediate charge air cooler and its ejection cooling.

Gas exchange control in the diesel with turbo charging solves the problem of combining the functions of ejection charge air cooling and turbocharger turbine control by the use of the energy from bypass junction pipe in a case of exhaust gases recirculation stop into the diesel cylinder. Turbo charging diesel working control with the use of bypass turbocharger turbine control and exhaust gases flow part recirculation solves one of the problems: exhaust gases recirculation or bypass turbine control. The use of two freestanding units makes their drive system much more complicated. Moreover, the separate drive for each of the units is needed. The drive system can be simplified by using of the integrated element, which is controlled by the specified program and performing exhaust gases recirculation and bypass turbine control in particular order.

In this case, it is necessary to use a part of exhaust gases for air circulation through intermediate charge air cooler with combination of functions of ejection cooling and bypass turbocharger turbine control due to the stop of the exhaust gases recirculation into the cylinder. In a case of bypass turbocharger turbine control stop, the device allows to use exhaust gases full flow energy after the turbine for air circulation through intermediate charge air cooler and its ejection cool down.

This system is explained in Fig. 1. Diesel 1 is connected with the intake manifold 2 and the air compressor 5 of turbocharger. The intermediate charge air cooler is located in the intake manifold 3. In front of the input device of the air compressor 5 is the multistage air filter 6 , through which the air comes to the compressor. Air compressor 5 is connected with the turbine 7 of the turbocharger. Intake manifold 9, connecting the turbocharger turbine with the diesel 1, in front of the turbine entrance 7 divided into two junction pipes. The junction pipe 8 connects the intake manifold 9 with the turbine 7 . The junction pipe 10 connects the intake manifold 9 with the gas flows control device, that are going from the junction pipe 10 and the turbine intake manifold 11 . Head pilot valve assembly for gas flows control contains the valve with two buckets 12 and 21 , which are connected by the thrust rod 20 . The spring 23 prevents valve movement in the cylinder. The valve cylinder has five clamping shoulders for connection with line tubes and junction pipes. On the one of the junction pipes clamping shoulders, there is the orifice 17 . Together with the mixing chamber 18 and the airline 19 it forms gas ejector, in which the element is exhaust gases flow, and environment is atmosphere air. The airline 19, connecting the mixing chamber 18 with the intermediate charge air cooler 
3 , has the entrance opening 4. Another junction pipe clamping shoulder is connected with the recirculation channel 22.

The system of inlet junction pipes 10 and 11 connection is the following: at first the inlet junction pipe 10 connects with the recirculation channel 22 , at the same time, the inlet junction pipe 11 connects with the orifice 17 of the outlet junction pipe 13. Then the inlet junction pipe 10 connects with the orifice 17 of the outlet junction pipe 13, and the inlet junction pipe 11 with the outlet junction pipe 13 . At the same moment, the inlet junction pipe 11 connects with the outlet junction pipe of the orifice 17 .

After diesel starting up under small and no-load conditions air flow comes from the atmosphere to the multistage air filter 6 , where is cleaned, and then because of the unchanging, created by the rotation of the wheel, comes to the air compressor 5 . In the air compressor the flow draws, at the same time pressure and temperature increase, and then comes to the intermediate charge air cooler 3 , where heat exchange between charge and atmosphere air takes place. Atmosphere air comes through the entrance opening 4 and circulates through the cooler.

Air circulation is possible, because of ejection effect, created by the flow of exhaust gases part through the orifice 17. After cooling in the intermediate charge air cooler 3, the air flows to the intake manifold 2 and then to the diesel cylinders. At the same time exhaust gases flow from the diesel cylinders goes to the intake manifold 9. Then it is divided into two unequal parts, providing bypass turbine control. The bigger part of the flow goes to channel 8 and then to the turbocharger turbine 7, the smaller part goes to the inlet junction pipe 10 of the device, regulating exhaust gases part flow movement. The thrust rod 20 and the buckets 12 and 21 are in the lower position because of the charge air low pressure under small and noload conditions. In this position, the smaller part of exhaust gases flows to the outlet junction

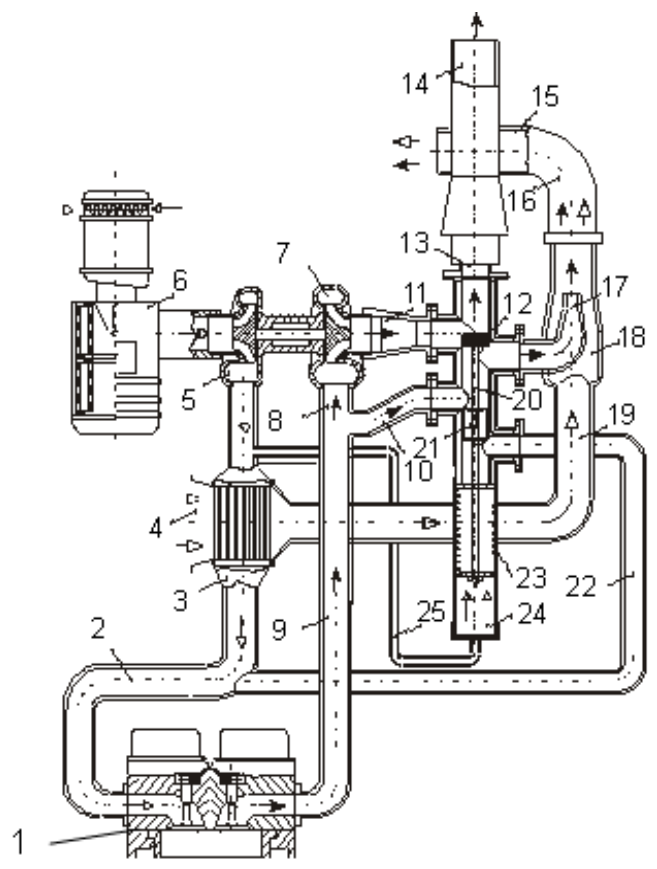

Figure 1: Gas exchange control system in a turbo charging diesel. 
pipe, connected with the recirculation channel 22, and then this part of the flow goes to the diesel cylinders through the intake manifold 2, providing recirculation of the element.

Charge air pressure rises along with load increase (normal and small load conditions) in the diesel. Pressure rises in the cavity 24, because of that the thrust rod 20 and the buckets 12 and 21 move up, closing the recirculation channel 22 and connecting the inlet junction pipe 10 with the outlet junction pipe of the orifice 17 . The inlet junction pipe 11 is connected with outlet junction pipe 13, and the bigger part of exhaust gases flows to the intake manifold 14 . Air circulation is possible because of the ejection effect, created by the flow of exhaust gases from the inlet junction pipe 10 , the orifice 17 , the mixing chamber 18 , the channel 16 , and the intake manifold 15 , providing bypass turbine control.

The smaller part of exhaust gases movement changes according to the correlation between air pressure after compressor and exhaust gases pressure before the turbine. Recirculation of the smaller part of exhaust gases is provided, if this correlation is less than unity. If the correlation is equal of greater than unity, the air ejection trough the charge air cooler is provided.

In a case of further load increase charge air pressure moves the thrust rod 20 with the buckets 12 and 21 in such way, that the bucket 21 closes the inlet junction pipe 10, thus the bypass turbine control stops. The bucket 12 closes outlet junction pipe 13, sending the full flow of exhaust gases after the turbine through outlet junction pipe of the orifice 17, the mixing chamber 18 , and channel 16 to the intake manifold 15 . At the same moment, the charge air cool down is intensified, due to bigger use of air through the intermediate charge air cooler.

\section{THE GAS EXCHANGE CONTROL DEVICE IN THE TURBO CHARGING DIESEL}

The particular device, providing the smaller part of exhaust gases movement before the turbine and the bigger or full flow of exhaust gases after the turbine, realizes the concerned way of turbo charging diesel working control. The construction of this device is explained in Fig. 2. The device consists of two parts: valve motion 7 and control cylinder 3 .

The valve motion body 7 has three channels 8,17 and 19, two of which 17 and 19 are situated opposite the third bypass channel 8 . The axis of the third channel is between the axis of two other channels 17, 19 and the element with two buckets 12 and 21 , which are connected by the thrust rod 20. The valve motion body has two more channels 10 and 13 . The axis of the channel 13, situated at the flat end of the body, coincides with its axis. The axis of the channel 10 is perpendicular to the axis of the body.

The control cylinder 3 has the connector 1 for charge air delivery. The connector 1 is in the cover 2. Under the charge air pressure from one side and the pullback spring 23 from another, the additional thrust rod 22, connected with the bucket 21 by the main thrust rod 20 and the bucket 12, moves in the cylinder. The opposite end of the pullback spring 23 leans on the restricted dividing 5. The restricted dividing is used a bottom of the control cylinder 3.

The pullback spring 23 location in cold working cavity of the control cylinder can be explained by the necessity to increase its efficiency.

The device works in the following way. Before the diesel starting up and its working under small and no-load conditions the element, including the buckets 12 and 21, connected by the thrust rod 20, additional thrust rod 22 with stop end 4, is held in the position I (Fig. 2) under the force of the pullback spring 23 , as the charge air pressure is low in the control cylinder 3 

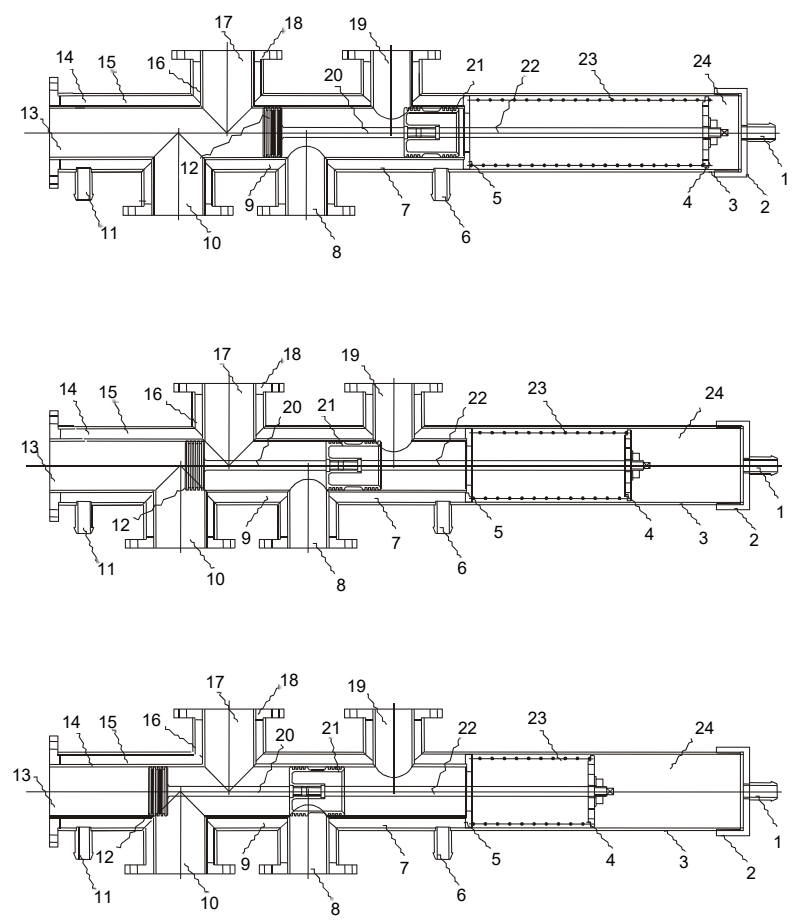

Figure 2: Exhaust gases control in gas exchange system valve motion device. Top: Position I; Middle: Position II; Bottom: Position III.

cavity 24 . In this position, the bypass channel 8 is connected with the channel 19 , and the smaller part of exhaust gases, limited by the area of passage and the change of pressure between inlet and outlet manifold, recirculates into the diesel cylinders.

Correlation between charge air pressure and exhaust gases pressure is less than unity. The channel 10 is connected with channels 13 and 17, which helps the biggest part of exhaust gases to flow through the channel 13 to the intake manifold 14, and through the channel 12 to the orifice for air ejection through the intermediate charge air cooler.

Gas temperature before the turbine rises under the normal and small load conditions, which causes turbocharger rotor wheel rotation frequency increase and charge air pressure raise. Charge air pressure raise in the control cylinder 3 cavity 24 makes the element to move against the spring 23. Correlation between charge air pressure and exhaust gases pressure becomes equal and then greater than unity. The bucket 21 closes the channel 19; the bucket 12 opens the channel 17. After completion of this process the element is in position II (Fig. 2 ), in which the bypass channel 8 is connected with the channel 17, and the channel 10 with the channel 13. The connection of channels 8 and 17 allows the smaller part of exhaust gases to flow to the orifice for air ejection through the intermediate charge air cooler. The connection of the channels 10 and 13 helps the bigger part of exhaust gases to flow to the outlet manifold 14. 
Further load increase (overload mode) raises the turbine capacity and charge air pressure, created by the compressor. The charge air pressure in the control cylinder 3 cavity 24 continues to rise, which makes the element to move further. Correlation between charge air pressure and exhaust gases pressure is much greater than unity. The bucket 21 starts to close the bypass channel 8 , the bucket 12 closes the channel 13, and the channel 10 connects with the channel 17. After completion of this process the element is in position III (Fig. 2). Thus, bypass control stops and the full flow of exhaust gases goes to the turbocharger turbine. After the turbine the full flow of exhaust gases through the channels 10 and 17 goes to the orifice for air ejection through the intermediate charge air cooler.

\section{EJECTION CHARGE AIR COOLING PECULIARITIES}

The use of the ejector as a source of air flow can be explained by its several peculiarities. The ejector has simple construction, can work with wide range of gas characteristics, and allows controlling easily the working process and changing working modes [4, 5]. It is widely used in different technical spheres. It is often used for constant air flow in channels or rooms, and thus works as a ventilator for cooling, provided by the radiator in the systems of liquid cooling in internal combustion engines, dust-removal from dirt collectors and ventilation of engine rooms and cabins in transport and traction vehicles.

The use of ejector in the charge air cooling system of the turbo charging diesel allows providing of its high sustainability. Such system automatically adapts to the air temperature, has simple construction and no moving parts. The use of ejection cooling system provides mixing of exhaust gases with air, and their temperature reduction. As a result, ecological indexes of the diesel improve. The ejection charge air cooling reduces the loss of diesel capacity on function of gas exchange. This article dealing with the problem of ejection charge air cooling system use in the "air-to-air" type cooler of the turbo charging diesel.

The ejection charge air cooling system in diesel is performed in the following way, Fig. 3. The air from the atmosphere flows to the air-cleaner 4, and then to the compressor 5 . In the compressor it draws, at the same time pressure and temperature increase and then comes to the intermediate charge air cooler 3 , where heat exchange between charge and atmosphere air takes place.

Air circulation is possible, because of ejection effect, created by the flow of exhaust gases part through the orifice. After cooling in the intermediate charge air cooler 3, the air flows from the compressor 5 to the intake manifold 2 and then to the diesel cylinders. The exhaust gases flow from the diesel cylinders goes through the intake manifold 7 to the turbocharger turbine body 6 , where heat energy of exhaust gases is conversed to the mechanical energy of the turbine wheel rotation.

We should study the principles of ejection cooling to prove the possibility of ejector, which utilize exhaust gases energy, use as a source of cooling air flow through the CAC. Program complex "SolidWorks" allows to determine the type of changes in gas mixture and in its components, Fig. 4.

The use of ejector in the charge air cooling system of the turbo charging diesel allows providing of its high sustainability. Such system automatically adapts to the air temperature, has simple construction and no moving parts. The use of ejection cooling system provides mixing of exhaust gases with air, and their temperature reduction. As a result, ecological indexes of the diesel improve [6]. The ejection charge air cooling reduces the loss of diesel capacity on function of gas exchange. 


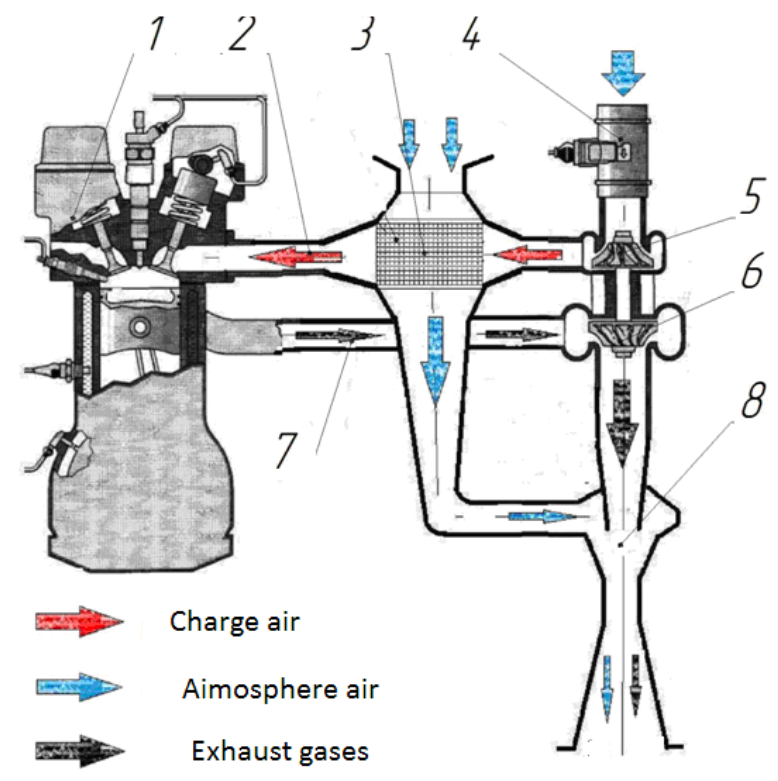

Figure 3: Ejection charge air cooling system in the diesel: 1-diesel, 2- inlet manifold, 3charge air cooler (CAC), 4- air filter, 5- compressor, 6-turbine, 7-outlet manifold, 9-ejector.

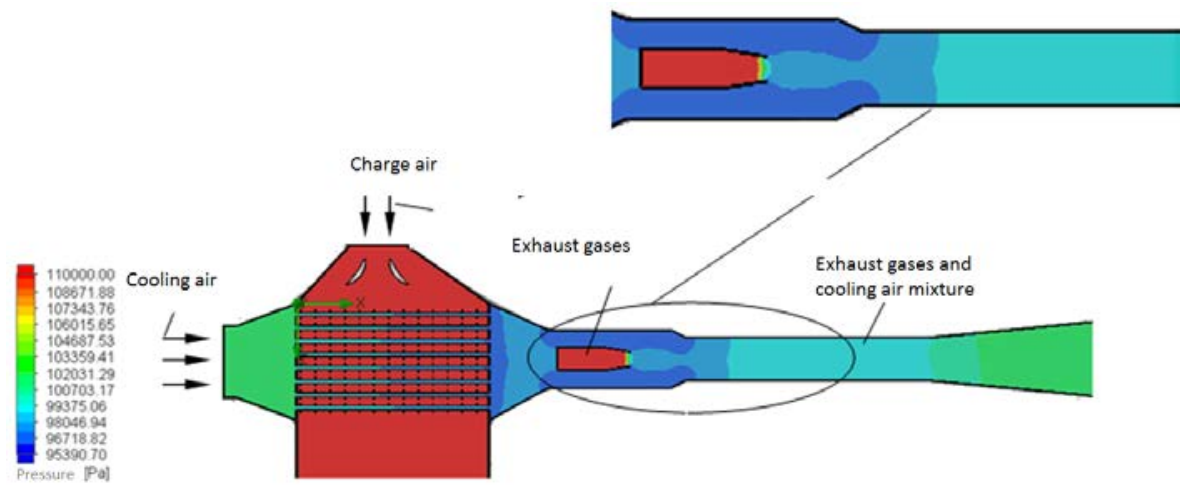

Figure 4: Gas mixture and its components pressure change.

\section{CONCLUSION}

Analysis of gas exchange processes in turbo charging diesel and the ways of their control shows that the problem of exhaust gases energy use is not completely studied. The use of the device for the recirculation control, bypassing and exhaust gases ejection simplifies the gas exchange system. 
Availability of sufficient amount of exhaust gases energy allows its use in the ejection device for effective cooling air circulation through the charge air cooler under full-load curve conditions.

As a result of gas exchange system improvement, the gas flows distribution control is simplified, emissions with exhaust gases, capacity input on charge air cooling in main working modes are reduced, and fuel efficiency is improved.

\section{REFERENCES}

[1] Isenburg, R., Munzenmay, M H. \& Kull, M., Diesel-Speicher-einspritzsystem Common Rail. Technische Unterrichtung. 2. Ausgabe, November. Robert Bosch GmbH: Stuttgart, 49 s, 1998.

[2] Petukhov, Y.V., Lazarev, Y.A., Lavrik, A.N., Pavlov, A.N., Mitsyn, G.P. \& Red'ko, I.Y., A adjusting device to the bypass turbine and exhaust gas recirculation at a turbocharged diesel engine. RF Patent number 2159340 C1, 7 F 02 B 37/12, 37/18. Publ. 20.11.2000.

[3] Sarkar, J., Ejector enhanced vapor compression refrigeration and heat pump systems. Renewable and Sustainable Energy Reviews, 16(9), pp. 6647-6659, 2012. doi: 10.1016/j.rser.2012.08.007.

[4] Zeyghami, M., Goswami, D.Y. \& Stefanakos, E., A review of solar thermo-mechanical refrigeration and cooling methods. Renewable and Sustainable Energy Reviews, 51, pp 1428-1445, 2015. doi: 10.1016/j.rser.2015.07.011.

[5] Nesbitt, B., Handbook of Pumps and Pumping: Pumping Manual International. Elsevier Science, p. 470, 2006

[6] Lin, C.A.B., Li, Y.A., Cai, W.B. \& Yan, J.B., Experimental investigation of the adjustable ejector in a multi-evaporator refrigeration system. Applied Thermal Engineering, 61, pp. 2-10, 2013. doi: 10.1016/j.applthermaleng.2013.07.045. 